\title{
Numerical investigation of bridges with the aim of condition assessment in applying the Deformation Area Difference method (DAD-method) and selecting appropriate measurement techniques
}

\author{
D. Erdenebat \& D. Waldmann \\ University of Luxembourg, Laboratory of Solid Structures, Luxembourg \\ F. N. Teferle \\ University of Luxembourg, Geophysics Laboratory, Luxembourg
}

\begin{abstract}
Condition assessment of existing road bridges gains ever increasing importance today as bridges are getting older and the inflow of heavy traffic is constantly increasing. The further development of recognized techniques and the development of new methods for early and accurate detection of damage to the structure are made possible by means of innovative technological progress. In this contribution, the principles of Deformation Area Difference Method (DAD-Method) for condition assessment of bridges are presented. This method is based on the further processing of measured and computed deformation values. The application of the DADMethod requires a precise recording of the deflection of a load-deflection test. On the basis of theoretical calculations, this method has allowed to identify as well as to localise damage to a structure. The DAD-Method is independent of a reference measurement and insensitive to global influences such as temperature fluctuations. For precise detection of deformations, the most modern measuring instruments and methods like photogrammetry, total stations, displacement sensors, strain gauges and levelling are compared to each other. In collaboration with the appropriate measurement technology, the localisation of damage in bridges becomes possible.
\end{abstract}

\section{INSTRUCTION}

The rapid technological progress in the last decades has revolutionized the daily life of people. At the same, time, this has allowed research to develop innovative technologies such as Finite Element Model (FEM) based structural modelling and precise condition assessment of existing structures. In particular, bridges require alternative methods for monitoring, damage detection and corrective maintenance in order to provide safe operation under increasing traffic inflows and to offer a simple, realizable conservation strategy.

The most common damages to bridges occur due to global and local impacts like corrosion, carbonation, alkali-silica reactions, leaching (Stein, 2004), oil and grease penetration, crystallization, acids and salts, fatigue, high temperature fluctuations, modification of founding conditions, overloading, shrinkage and creep as well as water penetration. For the detection and assessment of these damages, the following procedures are applied and developed: Ultrasound Echo Principle, Impact-Echo technique, impulse response (Davis, et al., 2003), Georadar, Microwave moisture measurement, Infrared thermography, halfcell potentials, Galvanostatic pulse measurement and chloride concentration measurement (Strategic Highway Research Program SHRP 2, 2013). Monitoring indeed has a large potential for improvement of structure preservation, but it is linked to the following necessary development progresses: possibility of maintenance and exchangeability due to limited lifespan, at the moment only in form of prototypes, the essential work relies on the engineering work, high personal, maintenance and installations costs (Bergmeister \& Wendner, 2010). Dynamic tests on bridges are often performed in the context of particular research projects. However, the lack of reference measurements of existing bridges and the limited knowledge of component properties make dynamic tests difficult in the application (Maas, et al., 2012). This study represents a simply applicable method with the objective of closing the safety gap and reducing the additional effort of regular condition assessment methods. The method is called Deformation Area Difference Method (DAD-Method) and is based on the one hand on modern FEM-calculations and on the other hand on future-oriented measuring techniques. The DAD-Method uses basic information of load-deformation tests like deflection, inclination angle and curvature of a loaded structure. With this information, the detection and localization of damage on a structure is possible. The DAD-Method is not only easily applicable, but also independent of global impacts such as the asphalt layer influencing the overall stiffness or temperature fluctuations. The main requirement for the application of this method is to ensure a precise deformation measurement of the structure. In order to assess the suitability of the 
measuring techniques in combination with the DADMethod, different modern measuring instruments and methods are tested using laboratory tests.

In this report, the results of the conducted investigations are presented. The test specimen is a reinforced concrete beam (Figure 1). In a first step, the beam was lifted on one side in order to compare the measuring techniques out their resolution to each other.

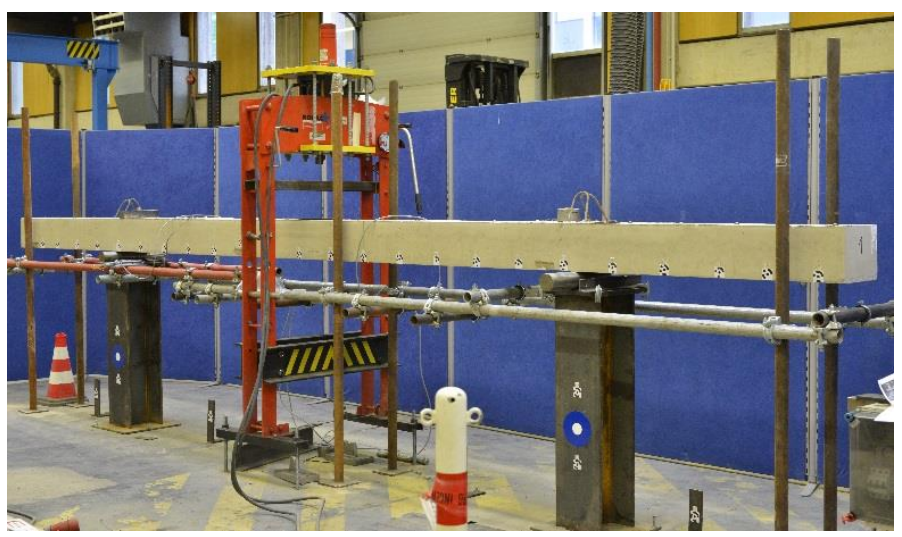

Figure 1. Test specimen: reinforced concrete beam

\section{APPLIED MEASUREMENT TECHNOLOGIES}

\subsection{Digital Levelling}

The levelling instrument employed in this study is a "Leica DNA03", which is generally utilised for precise height measurements (Figure 2). This instrument compares on internal reference barcode with the barcode registered on the levelling rod, which is placed vertically on a point to be measured. Through a correlation process the height reading is determined. Several automatic internal readings are performed for each height measurement whereby a direct control of the verticality of the rod is given during the time of measurement. According to the instrument specification the standard deviation for the height measurement is $0.30 \mathrm{~mm}$ for a $1 \mathrm{k}$ double levelling (Leica Geosystems AG, 2006). The significant advantages of a digital level are the high accuracy, the simple and efficient measurement, and the quick data evaluation. The measurement time for the 24 points is about 10 $20 \mathrm{~min}$ and the evaluation takes about 30-60 min, whereby the latter could be automated to a high degree.

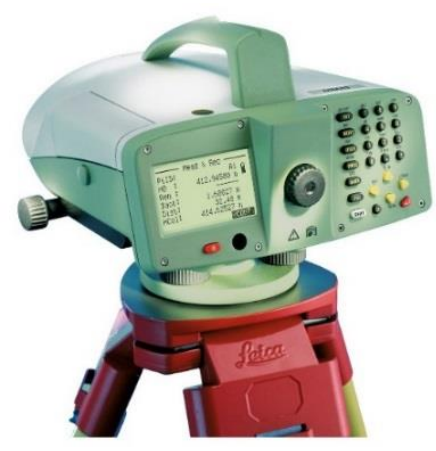

Figure 2. Digital Level Leica DNA03

(Leica Geosystems AG, 2006).

\subsection{Total station}

The total station employed in this study is a "Leica TS30" which figures among the latest generation of high-precision total stations from Leica Geosystems (Figure 3). Thanks to its high flexibility, it has proven its effectiveness on many occasions during the experiment. Besides the deformation measurements the total station was also used to coordinate the reference points for the photogrammetry as well as for the camera calibration. According to the manufacturer, the TS30 allows a precision of up to $0.15 \mathrm{mgon}\left(0.5^{\text {" }}\right)$ for angle measurements and $0.6 \mathrm{~mm}+1 \mathrm{ppm}$ for distance measurement (Leica Geosystems AG, 2009). Using target reflectors which were positioned on the test beam, it was possible to achieve time-saving and precise results. A decisive advantage of this instrument is the provision of three-dimensional coordinates. The measurement of the 25 targets takes about 20-30 min using the automatic target recognition. In this study the evaluation took about 2-3 hours, which can be highly automated to give results in near real time.

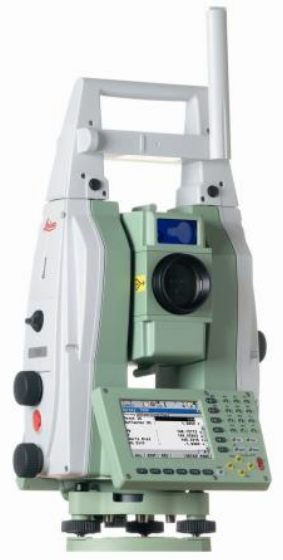

Figure 3. Total station Leica (Leica Geosystems AG, 2009) 


\subsection{Inductive displacement sensors}

Inductive displacement (Figure 4) sensors have gained recognition in industry as well as in research due to their robustness and high precision (Hottinger Baldwin Messtechnik GmbH, ). Displacement sensors in dependency to the nominal displacement not only provide a precise measurement, but also important information about time. They are suitable for static and dynamic load tests. However, these sensors need a solid preconstruction which depending on the bridge structure can be very time-consuming or impossible to achieve. Moreover, the measurement is only performed locally at discrete points. To measure a continuous deflection curve, the effort grows immensely. On the other hand, the duration of measurement is fairly unlimited.

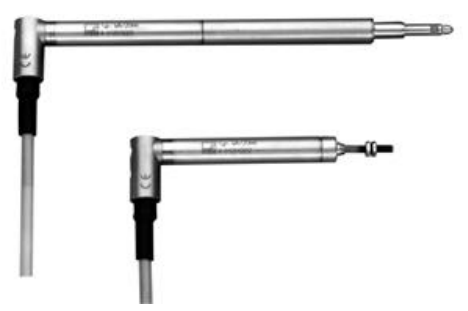

Figure 4. Displacement sensors WA T HBM (Hottinger Baldwin Messtechnik GmbH, ).

\subsection{Photogrammetry}

The rapid technological progress in the last decades is also clearly noticeable in the field of photography. Modern software products and high-resolution cameras provide research with new possibilities for image processing and the provision of highly precise threedimensional coordinates (Maas \& Hampel, 2006). Close-range photogrammetry is, for example, used in medicine, in police and juridical analysis, in architecture for the capture of protected monuments and in the automotive industry for the control of the manufacturing process up to driver assistance systems (Luhmann, et al., 2014). Within the framework of this project, a reflex camera Nikon D800 with a $50 \mathrm{~mm}$ lens as well as the software Elcovision 10 are used. Photogrammetry (specifically for this application) is impressive for its simple handling, the measurements in three-dimensional space and arbitrary position by simple pixel measurements (Figure 5). This corresponds for the $6.00 \mathrm{~m}$ long test specimen and a shooting range from the object of $5.00 \mathrm{~m}$, a collection of 12,500 pixels (measuring possibilities each $0.50 \mathrm{~mm}$ ). However, the high dependency on local conditions like lighting, reference measurement, as well as the quality of the camera calibration, which in turn depends on external measurements, are considered as disadvantages. Per measurement series about 30 pictures are taken and their evaluation could be automated to save time.

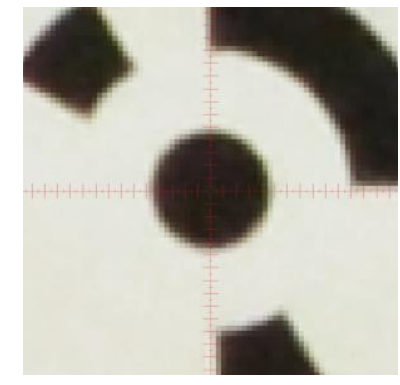

Figure 5. Pixel measurement with Elcovision 10.

\section{DAD-METHOD}

The objective is to develop a method which allows damage detection in structures using a non-destructive load test. The DAD-Method tries to detect and locate a discontinuity in the deformation courses of a static system by normalisation of individual areas (here until $\Delta \mathrm{A}_{20}$ ) over the total area. During a nondestructive load test, the structure is loaded at the serviceability limit level, whereby only small deformations are observed. The application of this method provides the possibility to detect and show hidden discontinuities in deflections. The DAD-Method is demonstrated on the example of a two-span beam (Figure 6). The non-uniform two-span beam with a total length of $10 \mathrm{~m}$ was modelled in a FE-Program with a mesh length of $50 \mathrm{~cm}$. The mesh length provides the deformation values at spacing of $50 \mathrm{~cm}$ in the longitudinal direction of the structure. A difference can be observed between the damaged and undamaged system. In this example, a local damage is generated at the spot of element Nr. $16 x=7.75 \mathrm{~m}$ (Figure 6) by reducing the stiffness of the element to $60 \%$. However, the degree of damage is not detectable using the DAD-Method. Due to the calculation of deflections, and curvatures, the bending line is given as starting point. Initially, the first derivative of the bending line at the location of damage is determined. However, in most cases, the establishment of the second derivative of the bending line, the curvature, is needed to give a clear statement about the location of the damage. According to Figure 6, under consideration of the DAD-values, the damage to the two-span beam is detected at the position between $\mathrm{x}=7.0$ and $8.0 \mathrm{~m}$. The precision of the localisation (here $\pm 50 \mathrm{~cm}$ ) depends on the mesh density of the numerical computation. For in-situ measurements, this corresponds to the density of the measuring points on the girder. 

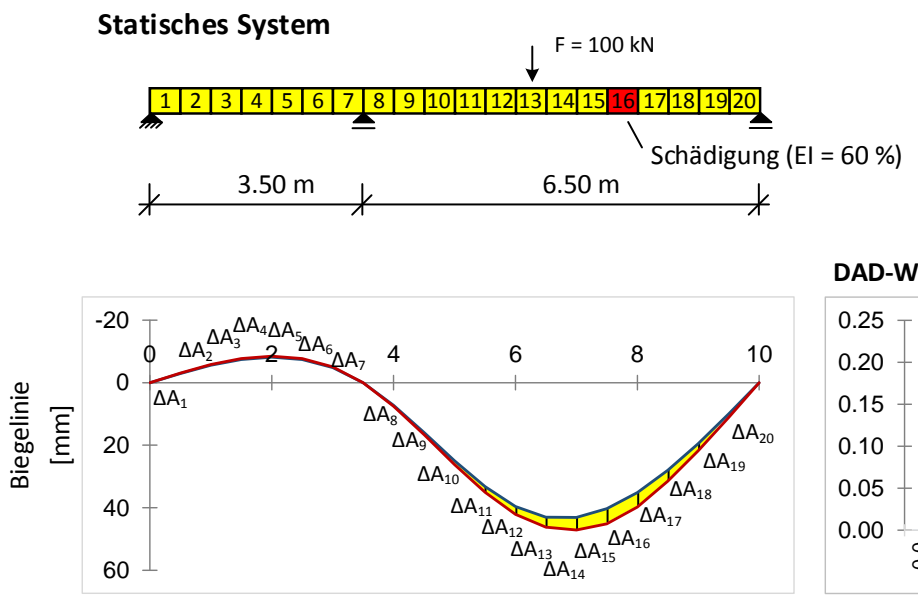

DAD-Werte aus der Biegelinie

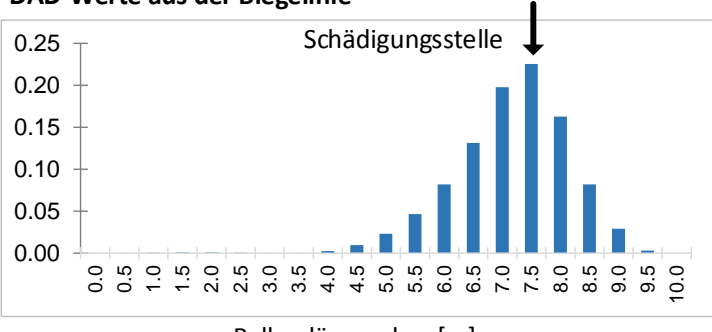

Balkenlängsachse [m]

DAD-Werte aus dem Neigungswinkel
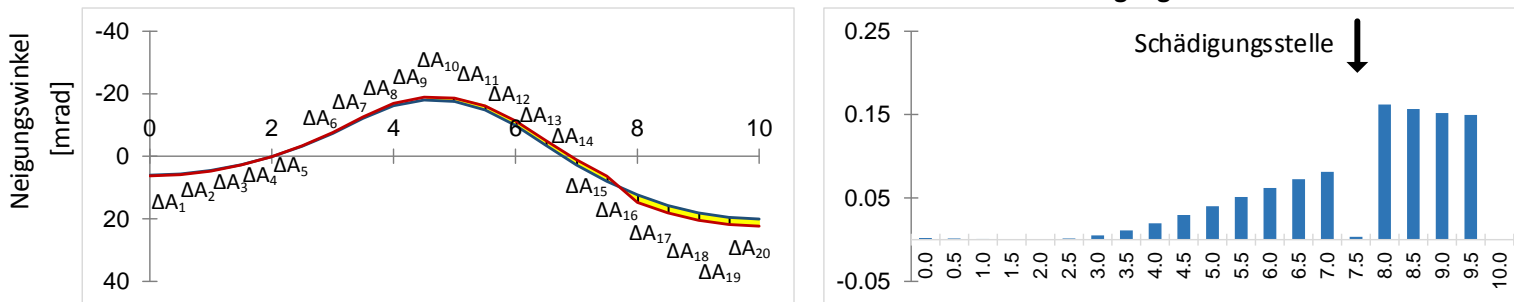

Balkenlängsachse [m]

DAD-Werte aus der Krümmung
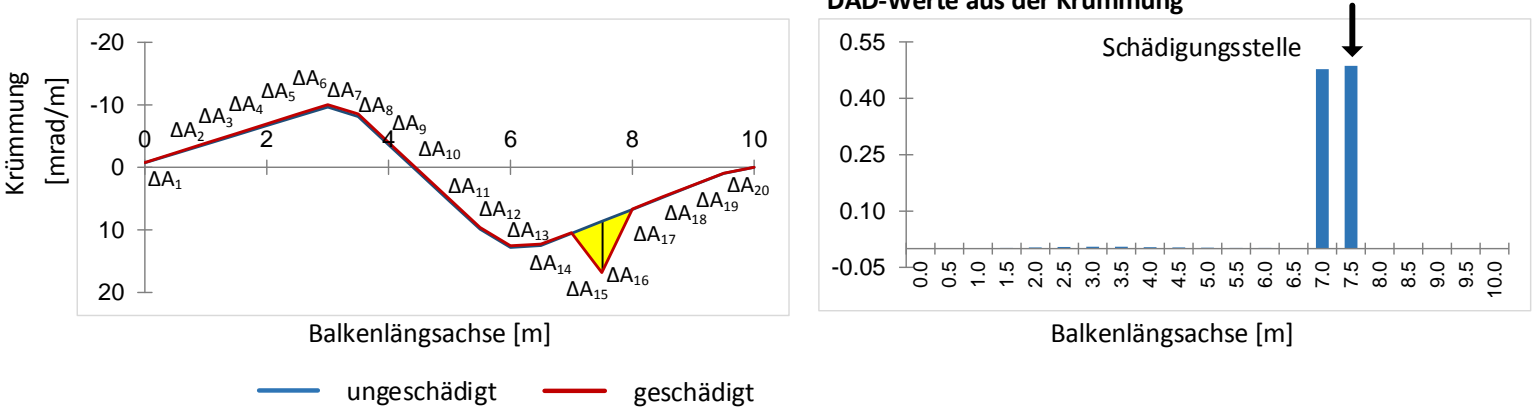

Balkenlängsachse [m]

Figure 6. DAD-Method on the example of two span girder.

\section{TEST BEAM AND TARGETS}

The test beam (Figure 7) prepared was firstly lifted by $2.50 \mathrm{~cm}$ in order to perform the first comparison of the applied measurement technologies. The center of rotation, respectively, the neutral axis of the girder is the left support at $\mathrm{x}=1.20 \mathrm{~m}$. On the girder were unilaterally fixed 31 targets for the close range photogrammetry (Figure 13), 25 targets for the total station and above the girder 24 benchmarks for the levelling (Figure 9). Additionally, different benchmarks are positioned at base level as well as at the support.
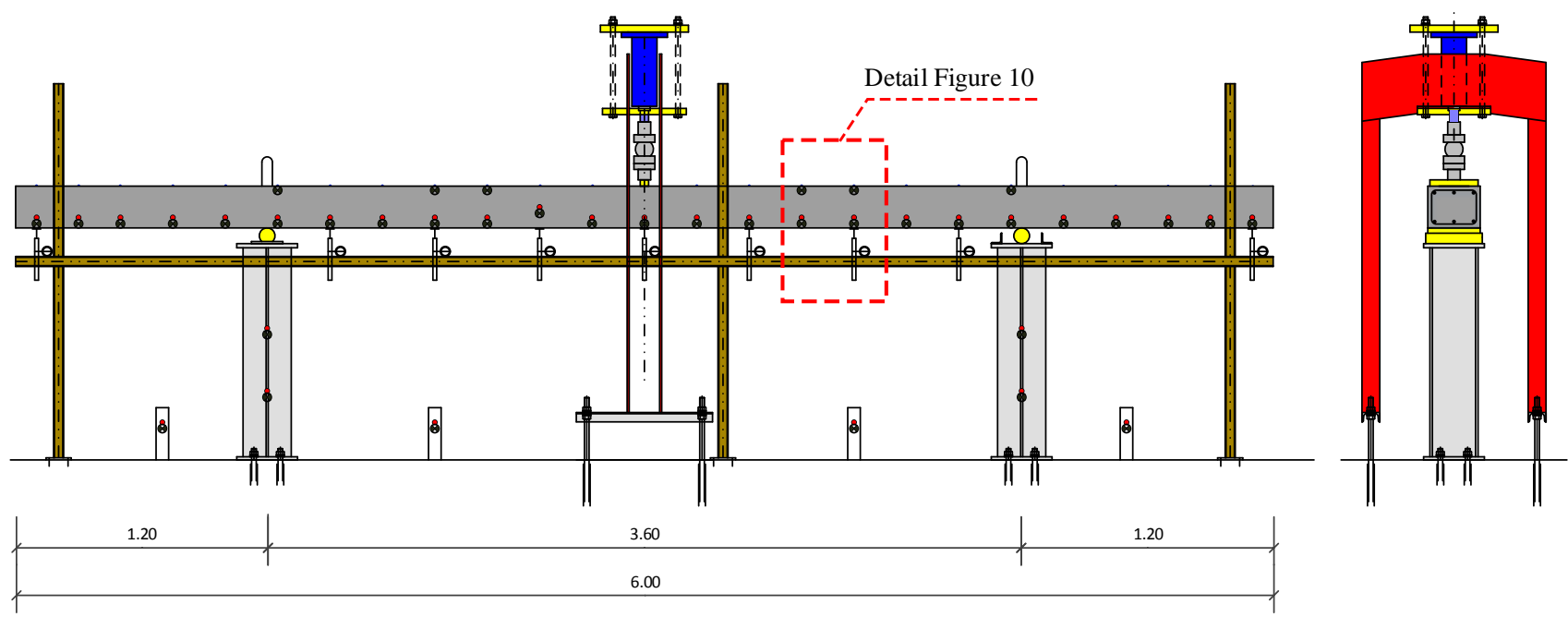

Figure 7. Test specimen: side view (left), cross section (right). 


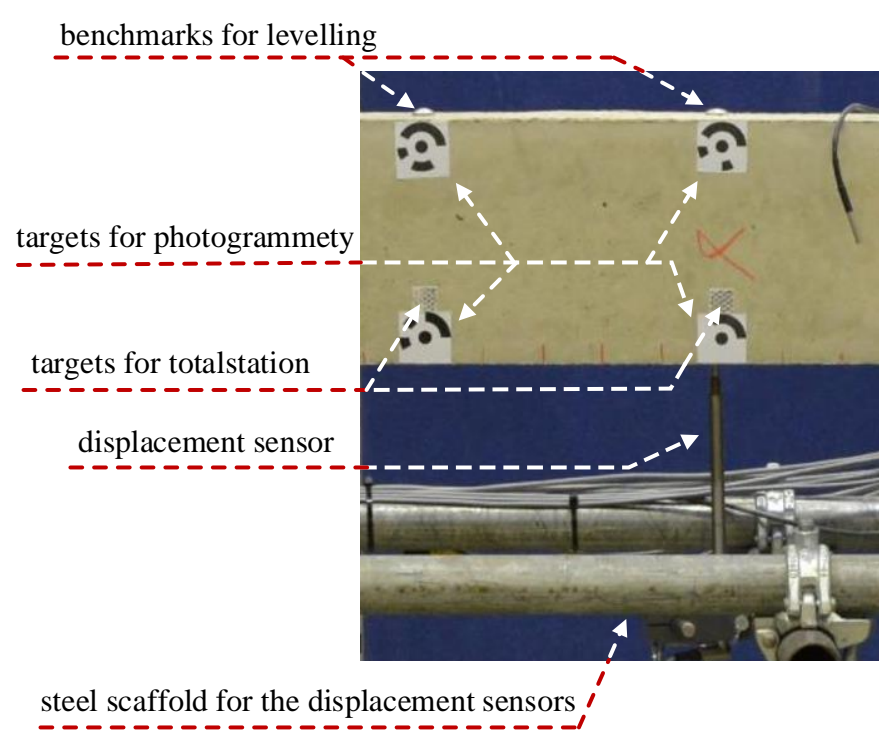

Figure 8. Detail: Position of the measuring points.

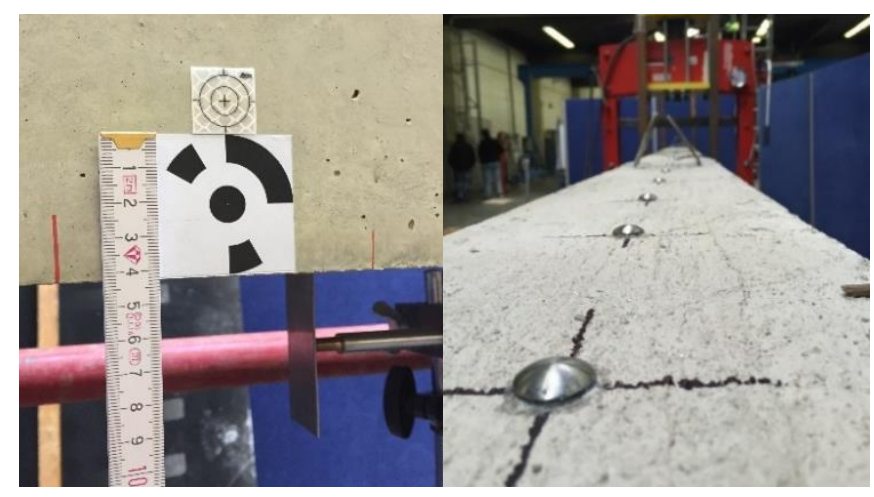

Figure 9. Targets for close range photogrammetry and total station (left figure), benchmarks for levelling (right Figure).

\section{DATA EVALUATION}

In the following, the results of the presented technologies are compared. As no load deformation test was performed only a one-sided lift of the girder was realised, the steel framework completely remained in state I. In other words, the tensile reinforcement did not experience any measurable strain/stress. Therefore, the evaluation of data from the strain gauges are omitted.

\subsection{Levelling}

The height measurement of the 24 measuring points using the digital level was performed from one position. In addition to the benchmarks on the beam, the reference points were measured at the beginning as well as at the end of each measurement series to provide a stability control for the observations. Although, the levelling needs two persons during the observation time, it remains the instrument with the least effort during the evaluation. Besides the simple handling of the level, this technology provides a high precision and a standard deviation of $0.04 \mathrm{~mm}$ was achieved for the observations.

\subsection{Total station}

In the framework of this experiment, the automatic target recognition of the total station was used. An invisible laser signal is sent to the reflective target and received by an internal CCD sensor. In order to reduce the time of measurement, the cross hairs are positioned at the middle of the target with a certain accepted tolerance. The residual error is mathematically accounted to the horizontal and vertical angle. The standard deviation for the observations in this study was computed to be $0.081 \mathrm{~mm}$.

\subsection{Displacement sensors}

As already mentioned in section 2.3 the evaluation of the displacement sensors provides an additional information, "the axis of time". During the experiment, the measurements were done at $10 \mathrm{~Hz}$. However, the measuring points are limited to the number of used displacement sensors and additionally, an additional stable substructure is required to fix them.

\subsection{Photogrammetry}

The results realised by close-range photogrammetry are very dependent from the boundary conditions like the employed camera, the camera calibration, the distance to the object, the lighting conditions and the quality of the recording. For the calibration, in a separate room, targets were positioned on a $3.00 \times 7.00 \mathrm{~m}$ white wall. There targests were measured using the total station (Figure 10).

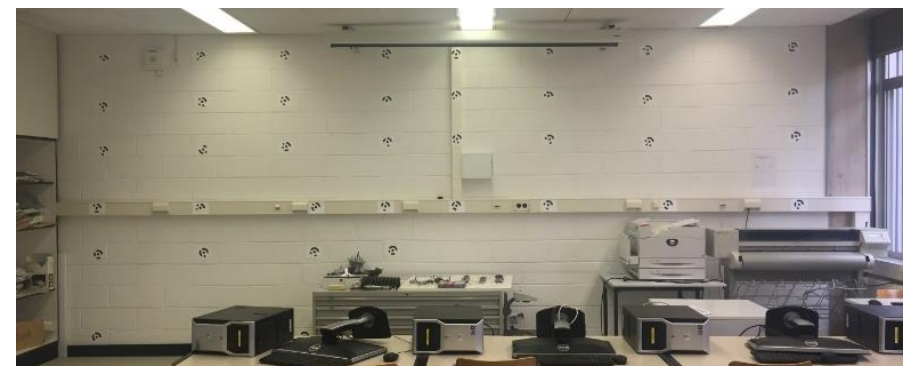

Figure 10. Calibration wall, University of Luxembourg.

It is preferable to also position targets on a plane offset to the wall surface to ensure a qualitative threedimensional measurement (PMS Photo Mess Systeme AG, 2012). The power strip, which sticks out the wall by about $7.00 \mathrm{~cm}$, provides the second plane. For the calibration of the camera, different variations were tested, for example, recordings with automatic or manual focus, recordings angular or perpendicular 
to the wall, different aperture depths etc. It is recommended to perform the recording from a semi-circular position (according to Figure 11) to the calibration wall. The optimal result is achieved by applying the following camera settings for the Nikon D800 with $50 \mathrm{~mm}$ lens: ISO 2000, aperture F/8, image dimension $7360 \times 4712$, manual focus, exposure time $1 / 200 \mathrm{sec}$. (for higher exposure time, it is recommended to use a stand and a remote release). The quality of the calibration can be seen in Figure 12, in which are indicated the accuracy of the camera data, correlations, the stability of the global orientation and the quality of the camera calibration.

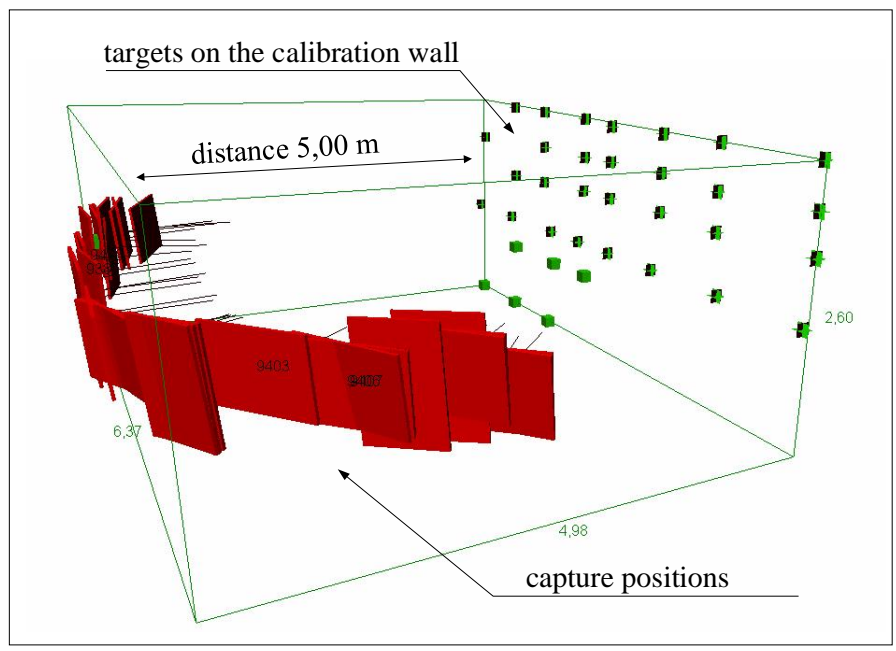

Figure 11. Perspective view: Position of recording to the calibration wall

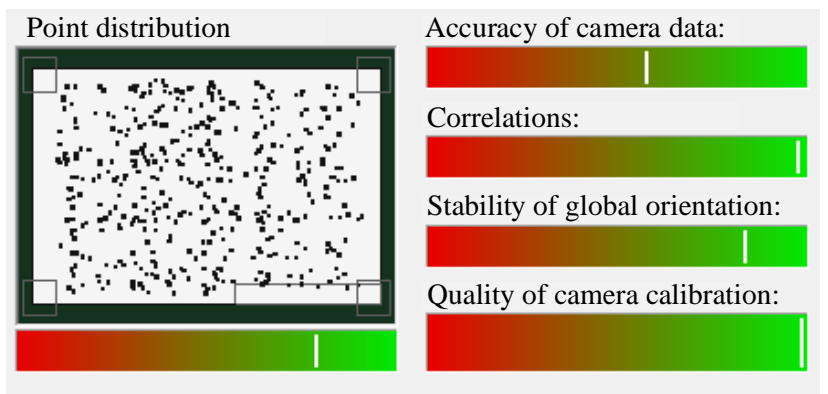

Figure 12. Point distribution and quality of the camera calibration

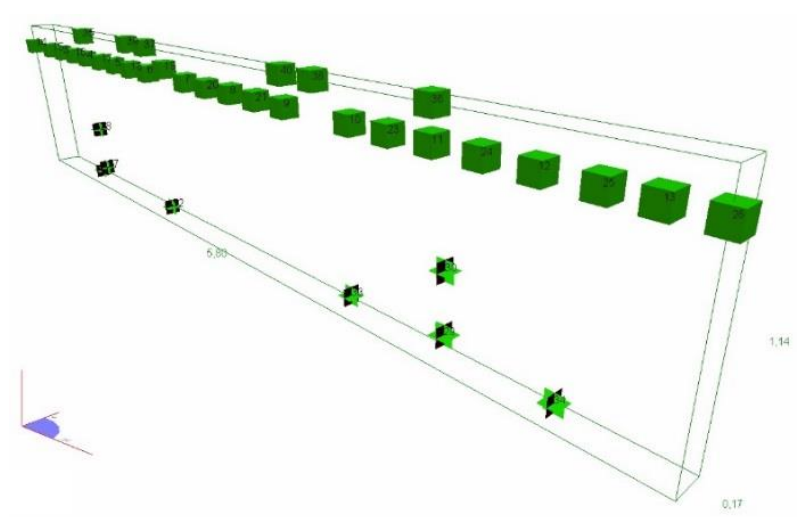

Figure 13. top (cubes): the targets (measuring points) on the test specimen, bottom: reference points (points for orientation).
The computed standard deviation for the photogrammetric observation is $0.170 \mathrm{~mm}$, but it has a high potential for improvement, which will be discussed in section 6 . The accuracy of the coordinates of the targets on the calibration wall and of the reference points near the beam affect the results of the photogrammetric measurements. Unfortunately, it was discovered that the coordinates of the targets on the calibration wall were of insufficient accuracy as they had been surveyed using total station with a lower accuracy than that of the TS30. This circumstance bears the largest potential for improving the results for the photogrammetric observations.

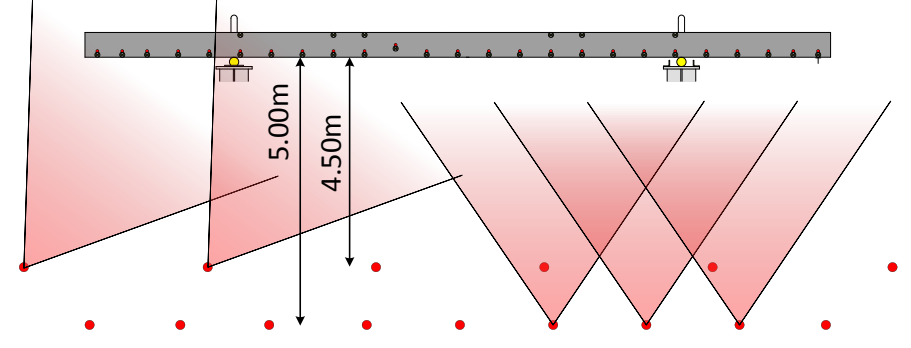

Figure 14. Schematic camera positions and angle of recording for Photogrammetry related to the beam.

\section{COMPARISON}

Altogether, three measurements were carried out over three days. Measurement 01: Reference positions and initial state, Measurement 02: one side lifted state, Measurement 03: the lowered state, corresponding to the initial state. The measuring points are distributed in the longitudinal direction from $\mathrm{x}=0.10 \mathrm{~m}$ to $\mathrm{x}=5.90 \mathrm{~m}$. Figure 15 shows the displacements between the initial state and the lifted state of the beam. At this scale, the results of the measurement techniques show good agreement. Figure 16 represents the deviations between the different measurement techniques with respect for the levelling results.

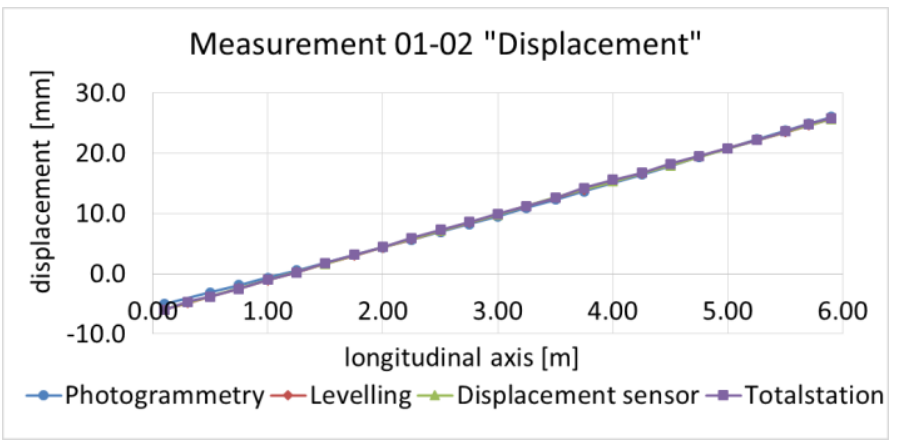

Figure 15. Measured displacements for Measurement 01 and Measurement 02. 


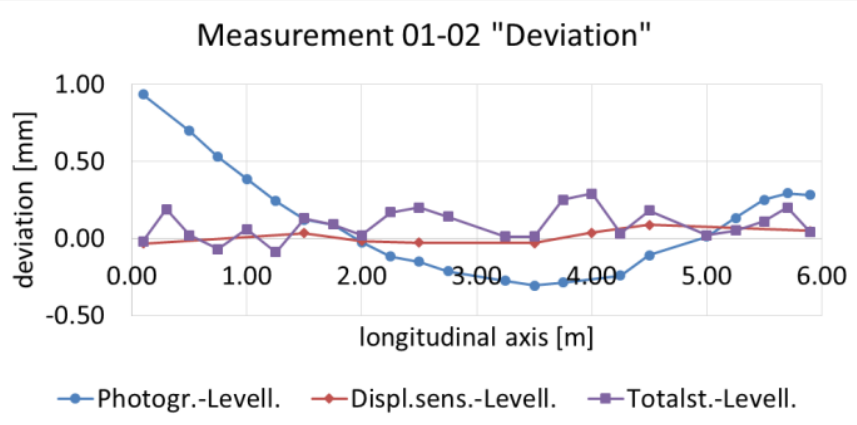

Figure 16. Deviation between each measurement techniques, levelling specified as reference

Figure 17 shows the difference between Measurement 01 and Measurement 03 i.e. the difference between the initial state and the lowered state. It can clearly be seen that the initial state is not fully restored after lowering of the beam. While the values from levelling and the displacement sensors almost coincide, a scattering of the values from the total station and photogrammetry can be observed. The measurement with the total station show a wider distribution of the values. However, the scattering behaves regularly over the 25 measurement points. This can be explained by the standard deviation as each measurement includes a measurement error. Figure 15 and Figure 16 show the more systematic behavior for the photogrammetric results. This might be explained due to the fact that the reference points are located bellow the beam. Therefore for further measurements, it is recommended to position additional reference points above the beam (for example on the wall of the experiment hall) to enclose the points of interest within the reference points. In Figure 17 the blue line corresponding to the values from photogrammetry shows an arch-like course instead of a uniform distribution (similar to the line from the total station). This indicates a systematic bias in the current results which is attributed again for the camera calibration or the location of the reference points with respect to the test beam. Hence, the full potential of the photogrammetric technique has not been reached.

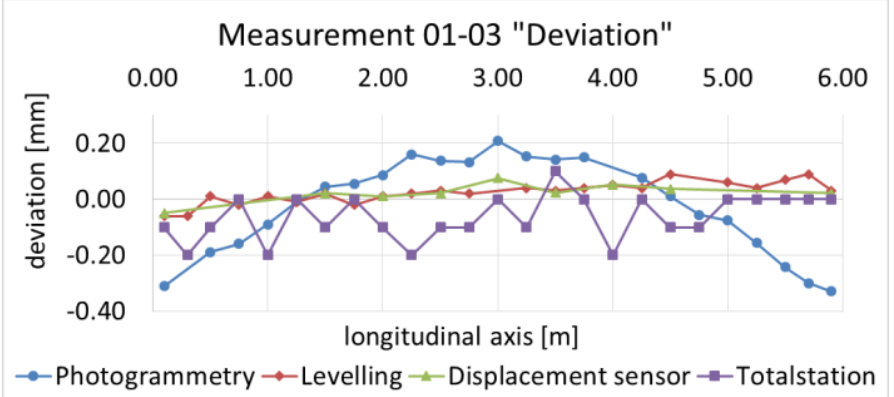

Figure 17. Deviation between Measurement 01 und Measurement 03
In the next test, the object is additionally captured from a camera position which is turned by 180 degrees to ensure that each aperture range encloses the left and right edge points of the beam and that at least 4 targets are overlapping in both pictures (manufacturer requirements). The quality of the calibration can be different depending on the distribution of the points (Figure 12) over the imaging sensor.

In Table 1 are listed the measured displacements of the one side lifting (Measurement 01 to Measurement 02).

Table 1. Measurement at selected points.

\begin{tabular}{|c|c|c|c|c|c|}
\hline$x$ & 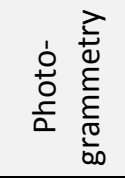 & 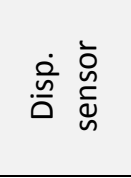 & 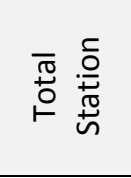 & & 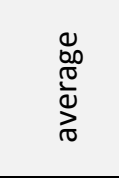 \\
\hline [m] & $\mathrm{w}[\mathrm{mm}]$ & $\mathrm{w}[\mathrm{mm}]$ & $\mathrm{w}[\mathrm{mm}]$ & $\mathrm{w}$ [mm] & $\mathrm{w}[\mathrm{mm}]$ \\
\hline 0.10 & -5.047 & -5.946 & -6.000 & -5.980 & -5.743 \\
\hline 1.50 & 1.791 & 1.637 & 1.800 & 1.670 & 1.724 \\
\hline 2.00 & 4.355 & 4.398 & 4.400 & 4.380 & 4.383 \\
\hline 2.50 & 6.948 & 7.127 & 7.300 & 7.100 & 7.119 \\
\hline 3.00 & 9.527 & 9.791 & 9.900 & - & 9.739 \\
\hline 3.50 & 12.284 & 12.620 & 12.600 & 12.590 & 12.523 \\
\hline 4.50 & 17.910 & 17.934 & 18.200 & 18.020 & 18.016 \\
\hline 5.90 & 26.041 & 25.712 & 25.800 & 25.760 & 25.828 \\
\hline
\end{tabular}

\subsection{Standard deviation}

By comparison of the standard deviations, a final statement on the quality of the measurements can be reached. The individual techniques are listed in Table 2 according to their order of precision. At the measuring point $\mathrm{x}=2.00 \mathrm{~m}$ the results of photogrammetry show the highest coherence, whereas at $x=0.10 \mathrm{~m}$ the lowest consistency can be observed. From the comparison of the measurement techniques, it can be concluded that the displacement sensors with a standard deviation of $0.034 \mathrm{~mm}$ represent the measurement techniques with the most precise results (Table 2). For better overview, these values are illustrated according to the Gaussian distribution (Figure 18 and Figure 19). The horizontal axis represents the measured displacement for the corresponding point, while the width of the curve is defined by the standard deviation.

Table 2. Comparison of the achieved technique-specific standard deviations.

\begin{tabular}{|c|l|c|}
\hline Rank & Methods & $\begin{array}{c}\text { Standard deviation } \\
{[\mathrm{mm}]}\end{array}$ \\
\hline 1. & Displacement sensor & 0.0342 \\
\hline 2. & Levelling & 0.0391 \\
\hline 3. & Total Station & 0.0810 \\
\hline 4. & Photogrammetry & 0.1697 \\
\hline
\end{tabular}




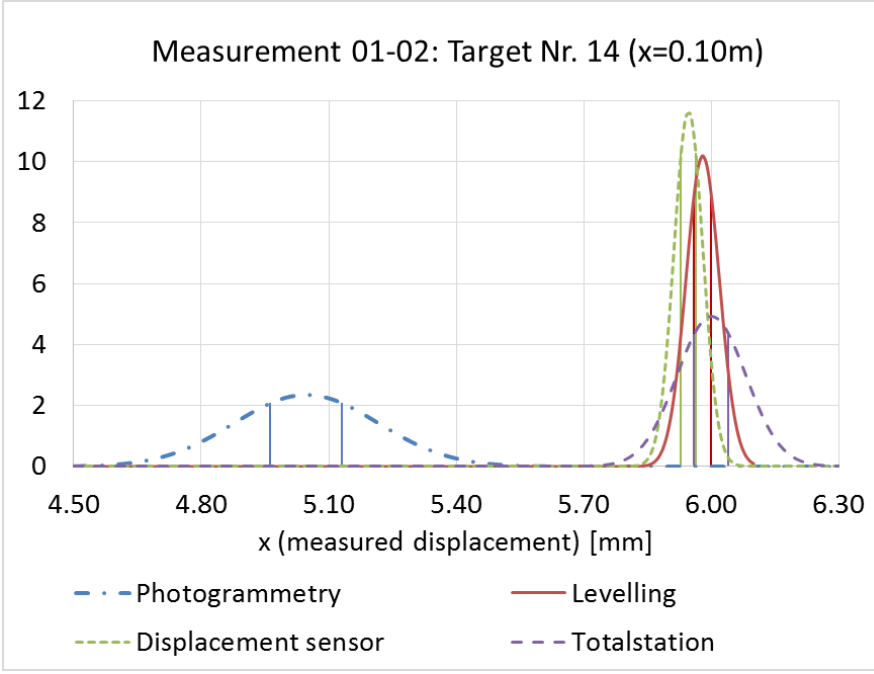

Figure 18. Standard deviation at measuring point $\mathrm{x}=0,10 \mathrm{~m}$

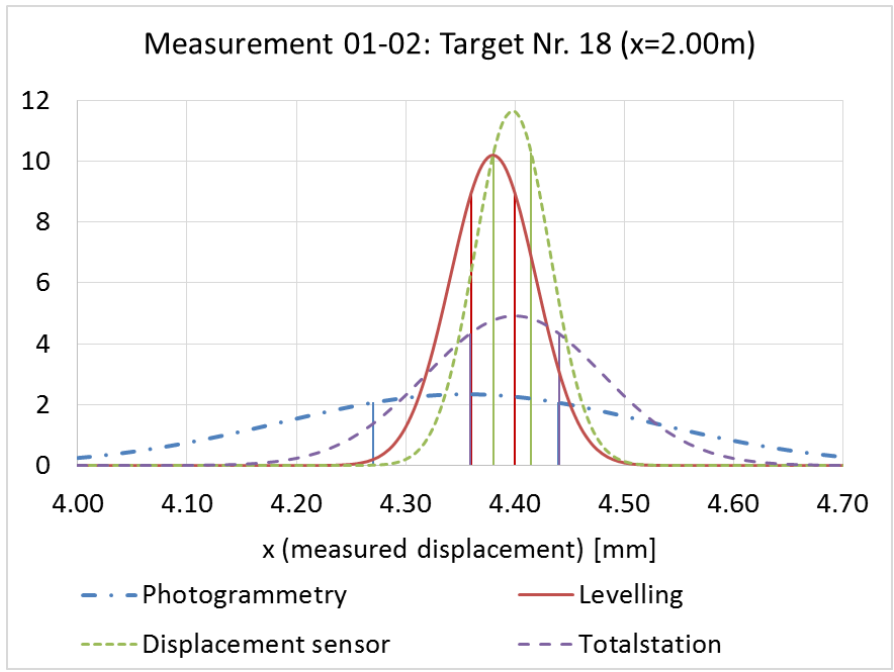

Figure 19. Standard deviation at measuring point $x=2,00 \mathrm{~m}$

\section{CONCLUSSION AND OUTLOOK}

In the presented study, the most recent measurement techniques were assessed and compared for their precision and applicability. The precisions of levelling and displacement sensors are comparable. Levelling has a high precision for the measurement and a simple handling. However, the observations are restricted to the measurements of heights. In comparison to the displacement sensors and levelling, the total station shows a lower precision, but it delivers measurement values in three-dimensional space in good quality (standard deviation $0.081 \mathrm{~mm}$ ). Photogrammetry has the potential to deliver more precise results using additional adjustments. These could come from for example: a better camera calibration, a better enclosure of the object by additional reference points and an optimisation of the points in the software. Important advantages of photogrammetry include the simple handling and the possibility of measuring an arbitrary number of points. In the context of this study, the next step is to assess the applicability of the DAD-Method to the presented test beam (using a load deformation test). In this experiment, a discontinuity will occur with increasing load in the system which will lead to crack initiation in the concrete tension area and the yield strength of steel will be reached. The crack initiation of the reinforced concrete beam induces a reduction of stiffness of about $50 \%$. The expected maximal displacement from the load deformation test is $2.50 \mathrm{~cm}$, whereas the deformation of about $0.90 \mathrm{~cm}$ is reached without stiffness reduction. The standard deviations of the applied measurement devices remains on average below the millimetre level. In other words, the detection of stiffness reduction using the DADMethod can be possible. This is an indication that with further progress a reliable detection of damages for bridge structures could be possible by means of the DAD-Method, FE-modelling and precise measurement techniques. For the latter it will be important to see to what degree the accuracies of the laboratory test can be achieved during the survey of existing bridge structures.

\section{REFERENCES}

Bergmeister, K. \& Wendner, R., 2010. Monitoring und Strukturidentifikation von Betonbrücken. In: Beton-Kalender 2010: Brücken - Betonbau im Wasser. Berlin: Ernst \& Sohn, pp. 245-290.

Davis, A., Skokie, Illinois \& Germann, C., 2003. Nondestructive Evaluation of Prestressed Concrete Bridges using Impule Response. Nondestructive Testing in Civil Engineering (NDT-CE).

Hottinger Baldwin Messtechnik GmbH, . WA Induktive Standard-Wegaufnehmer. s.l.:s.n.

Leica Geosystems AG, 2006. Leica DNA03/DNA10 User Manual. s.1.:s.n.

Leica Geosystems AG, 2009. Leica TS30 White Paper. s.l.:s.n.

Luhmann, T., Robson, S., Kyle, S. \& Boehm, J., 2014. Close-Range Photogrammetry and 3D Imaging. Berlin/Boston: Walter de Gruyter GmbH.

Maas, H.-G. \& Hampel, U., 2006. Photogrammetric Techniques in Civil Engineering Material Testing and Structure Monitoring, s.l.: s.n.

Maas, S. et al., 2012. Damage assessment of concrete structures through dynamic testing methods. Part 2: Bridge tests. Engineering Structures, pp. 483494.

PMS Photo Mess Systeme AG, 2012. Elcovision 10 Bedienungsanleitung. St. Margrethen: s.n.

Stein, V., 2004. Untersuchungen zur Optimierung und Bewertung des Auslaugverhaltens versinterungsrelevanter Stoffe aus Spritzbetonen als Beitrag zur Verbesserung der Umweltverträglichkeit, Bochum: s.n.

Strategic Highway Research Program SHRP 2, 2013. Nondestructive Testing to Identify Concrete Bridge Deck Deterioration, Washington D.C.: s.n. 